\title{
Article
}

\section{The Heightened 'Security Zone' Function of Gated Communities during the COVID-19 Pandemic and the Changing Housing Market Dynamic: Evidence from Beijing, China}

\author{
Ling $\mathrm{Li}^{1}\left(\mathbb{D}\right.$, Wayne Xinwei Wan ${ }^{1}\left(\mathbb{D}\right.$ and Shenjing $\mathrm{He}^{2, *}$ (I) \\ 1 Department of Land Economy, University of Cambridge, Cambridge CB3 9EP, UK; 11496@cam.ac.uk (L.L.); \\ xw357@cam.ac.uk (W.X.W.) \\ 2 Department of Urban Planning and Design, University of Hong Kong, Hong Kong 999077, China \\ * Correspondence: sjhe@hku.hk
}

Citation: Li, L.; Wan, W.X.; He, S. The Heightened 'Security Zone' Function of Gated Communities during the COVID-19 Pandemic and the Changing Housing Market Dynamic: Evidence from Beijing, China. Land 2021, 10, 983. https:// doi.org/10.3390/land10090983

Academic Editor: Thomas Maloutas

Received: 23 August 2021

Accepted: 16 September 2021

Published: 17 September 2021

Publisher's Note: MDPI stays neutral with regard to jurisdictional claims in published maps and institutional affiliations.

Copyright: (c) 2021 by the authors. Licensee MDPI, Basel, Switzerland. This article is an open access article distributed under the terms and conditions of the Creative Commons Attribution (CC BY) license (https:// creativecommons.org/licenses/by/ $4.0 /)$.

\begin{abstract}
The ongoing COVID-19 pandemic has left a strong imprint on many aspects of urban life. Gated communities (GCs) in China are less commonly perceived as a negative and segregated urban form of community compared to other contexts, owing to their wide variety and relative openness. Yet, the enhanced security zone function and the popularity of GCs, along with the heightened segregation and exclusion effects, mean they are most likely to emerge in post-pandemic urban China because of the perceived effectiveness of GCs in preventing health risks by excluding outsiders during the pandemic. Drawing on empirical data from Beijing, this research presents strong evidence for a strengthened perceived 'security zone' effect of GCs during the pandemic. Given that rigid pandemic control measures were organized at the community level, a large-scale household survey in Beijing suggests that residents commonly recognise the effectiveness of GCs in security control and show a strong preference for GCs over open communities after the pandemic, even though there is a lack of direct evidence of reduced COVID-19 risk in GCs. The heightened perceived 'security zone' function of GCs has shown a significant impact on the housing market, evidenced by an increase of $2 \%$ in the housing prices for GCs, compared with those of open communities. The rising popularity of GCs is also evidenced by a significant increase in property viewings by potential homebuyers and smaller price discounts in actual transactions in gated communities vis-à-vis open communities. We argue that the rising risk-averse sentiment in the post-pandemic era has given rise to the popularity of GCs. This study provides timely and fresh insights into the changing meaning of GCs in post-pandemic China.
\end{abstract}

Keywords: COVID-19 pandemic; gated community; security zone; housing price

\section{Introduction}

The global prevalence of gated communities (GCs), to which public access is restricted, has attracted scholarly attention for decades [1]. GCs not only emerged as an innovative form of living catering to residents' various demands (e.g., security, high-quality housing, all-inclusive lifestyle and conspicuous consumption) but also revolutionized neighborhood governance [2-5]. Despite the growing popularity, GCs have been harshly criticized by urban theorists for producing negative social effects, for example, exacerbating segregation and exclusion through erecting walls and gates, and their encroachment into public space $[1,6,7]$.

In China, the proliferation of GCs is associated with unique cultural and institutional forces and, thus, entails different interpretations. Since the late 1990s, most housing estates in China have taken a gated form, resembling the walls, gates, guards, and to some extent, the self-governance of GCs in the West. However, Chinese GCs are distinct in their 
pervasiveness and wide varieties, as well as the public's relatively neutral attitude and tolerance. Although GCs of large sizes are usually blamed for dampening the connectivity within the city and contributing to traffic congestion [8], they are rarely criticized for exacerbating social segregation and exclusion in China. This is often considered as the result of a long tradition of urban enclosures and the dominant role of the state [9-11]. Gating in new housing developments is implicitly endorsed by the Chinese state and promoted as a national standard to enhance the provision of local public goods after the housing commodification [12]. Among the three main types of GCs identified by Blakely [1], (i.e., lifestyle, prestige, and security zone communities), security zone is perhaps the least emphasized function in the Chinese context for two reasons. First, different branches and organizations of local governments still take up the main responsibility of safeguarding public security, among which the residents' committee serves as a grassroots government organ at residential community level, rather than heavily relying on the GCs as reported in certain countries [13]. Different from other contexts, the security zone function of GCs in China is deemed mainly as psychological rather than practical [14-18]. Second, many GCs in Chinese cities do not enforce stringent access control as they are supposed to be, especially for the more affordable GCs and those converted from danwei (work unit) compounds, which render these GCs more akin to open communities despite their physical walls and gates. This also partially explains why GCs in China are less commonly discussed in the lexicon of segregation and exclusion as in international debates.

During the COVID-19 outbreak, China and many other countries imposed lockdown orders that required or encouraged households to stay at home to prevent virus transmission. What was unique to China was the stringent access control imposed on nearly all residential communities, either through a top-down order by the local government or bottom-up initiatives voluntarily organized by local residents $[19,20]$. Thus, the security zone function of GCs had been heightened. Evidently, given the existing security facilities and measures, e.g., gates, walls, and CCTV cameras, even though they were not fully utilized in the pre-pandemic era, implementing stringent access control in GCs was easier than in open communities. Amidst the COVID-19 pandemic, citizens' perception of GCs may have substantially changed because of the rising risk-averse sentiment, with significant implications for the housing market and urban socio-spatial patterns. However, these important issues have not been empirically examined and comprehensively understood. Therefore, drawing on the empirical data from Beijing, China, we aim to present a timely and updated understanding of the heightened security zone function of GCs during the pandemic and its implications for the housing market. This research is centralized on two interrelated questions: (1) How has Chinese citizens' perception of GCs concerning the security zone function changed due to the pandemic? (2) How does that affect the housing market dynamic? Drawing on our empirical findings in Beijing, we would also like to discuss the possible long-term implications for residential segregation and exclusion concerning the development of GCs.

The two research questions are addressed using online survey data and housing transaction data from Beijing. We conducted an online questionnaire survey among 975 Beijing residents and collected a dataset of 76,465 housing transactions during the COVID-19 outbreaks from 935 residential communities in Beijing. Changes in residents' perception of GCs' security zone function and the preference for GCs due to the COVID-19 outbreak are identified based on self-reported data from the online survey and an analysis of housing transaction data using a multi-period difference-in-differences (DID) model. It is established in the literature that people's perception can have a real impact on housing price $[21,22]$. In this study, the changing housing price dynamic related to key attributes of GCs is measured by the transaction price, the number of interested buyers and the discount from the listing price.

This study renews our understanding of GCs in China by examining the changes in the function of gating and people's perception towards it in the face of the COVID-19 pandemic, and quantitatively measuring the impact on housing price dynamic. Adding to 
the ongoing debates on how cities are affected by the COVID-19 pandemic globally [23-25], this study speculates on the possible implications for residential segregation and exclusion, which were perceived as less of a problem in China [9], associated with the development of GCs in Chinese cities. A growing sense of insecurity caused by the once-in-a-century health crisis might result in aggravated segregation in Chinese cities through excessive development of GCs with stringent access controls, which deserves further investigation.

This study contributes to the extant literature in two ways. First, to the best of our knowledge, this is the first study to quantitatively examine the features of GCs and their impacts on the housing dynamics in China. Although the emergence and effects of GCs in China have been an important theme in urban research, their impacts on the housing dynamics have not been quantitatively understood on a par with other contexts. Second, a hybrid method of survey analysis and statistical regression models is applied to understand the possible mechanisms and outcomes of the changing housing dynamic affected by the preference for GCs. The remainder of the paper includes a literature review of GCs in China and the impact on housing market dynamics and an introduction of data and methodology, followed by the discussion of empirical results. The final section concludes.

\section{Gated Communities in China and the Impact on Housing Market Dynamics}

GCs in China have proliferated with an exceptional size and speed unseen in any other countries [12]. There are two major types of Chinese GCs—-work unit (danwei) compounds and gated commodity housing estates. When China started the market-oriented economic reform in the late 1980s, work unit compounds were either privatized or replaced by modern gated commodity estates with diverse housing choices, high population density, and, more importantly, the flexibility to be traded in the housing market $[10,12]$. Since then, modern gated commodity housing estates have become a prevalent form of residence in China. Although researchers often recourse to mainstream theories derived from the Western context to explain the proliferation of GCs in China, the distinct features of China's GCs should be noted.

Firstly, notwithstanding that the prevalence of GCs in China can be attributed in part to the security concern, the gates, walls, and fences in China's GCs mainly provide residents a sense of security psychologically rather than functionally given that the crime rates in China are relatively low [14,15,26,27]. In neighborhoods where gates are considered insufficient to guarantee security, additional measures have to be installed [17]. For a large number of GCs, the provision of better services, as well as the sense of stability and homogeneity, are probably more important than simply the absence of crime $[14,26]$. In this sense, the security zone function of GCs is less applicable in China compared with other contexts that suffer from high crime rates, racial segregation, and wars [28-30].

Secondly, while the theory of club goods is a widely accepted explanation for the emergence of modern GCs in China, the indispensable role played by the state should not be overlooked $[10,26]$. The two major types of GCs in China were derived from different rationales-gating in danwei compounds was to 'reinforce political control and collective consumption organized by the state' under socialism [26], whereas gating in commodity housing estates owes more to the shift in housing and services provided to the more efficient club realm to cater to the surging demand from the middle-class and expatriates for a better quality residence [31,32]. Nonetheless, in both types of GCs, the state has played a fundamental role. Even in the post-reform era, the state rationalized the development of GCs by imposing national planning codes, as a way to relieve the local governments from the heavy burden of providing infrastructure and local public goods $[3,10]$.

Thirdly, while GCs raise serious concerns for social segregation in many locales, they are perceived as less of an issue in China due to their unique political and cultural contexts [9]. Admittedly, gating in the post-reform era strengthens community development by enabling private governance through which residents gain better control over their community lives [33]. However, this does not reduce the top-down control and state intervention through dominating land development [34] and reinforcing the functions of 
the grassroots state apparatus (the residents' committee) and the newly emerging homeowners' association $[33,35]$. The tight yet subtle control over GCs has helped reduce social segregation, as a close-knit network between GCs and other communities has been formed by the active involvement of grassroots state apparatus. Given the long history of urban enclosures with walls and fences, the cultural tradition of collectivism can account in part for the prevalence and tolerance of GCs in China [11]. Moreover, the wide varieties and large quantity of GCs in China also render a lower level of exclusiveness and segregation.

The prevalence of GCs in China and their distinct features have been well documented in the existing literature $[10,14,26]$. Yet these key features and their impacts on the housing dynamics have not been quantitatively understood on a par with other contexts. Few studies examining the housing price dynamic of GCs reveal its significantly positive effect on housing values. For example, in their studies of GCs in different regions of the United States, LaCour-Little [36] documented a 9\% price premium associated with GCs between 1980 and 1998, Bible [37] discovered a 6\% price premium for the period 1996-1998 and Pompe [38] reports a price premium of around 19\% over the period 2002-2005. A recent study in Ghana reveals a price premium of GCs ranging from $42 \%$ and $48 \%$ [39]. These wide variations in GCs' price premium across countries and regions suggest the importance and necessity of a close examination of the qualities and functions of GCs to better understand their impacts on housing price dynamic, which is currently still lacking in the studies of China's GCs.

To fill this gap, this study aims to capture the changing function and perception of GCs during the COVID-19 pandemic and quantitatively examine their impact on the housing market. It contributes to the literature beyond simply providing new evidence to understand the overall price premium of GCs. While the existing literature generally relies on dichotomous price comparison between gated and open communities, it is difficult to differentiate the price premium generated by various functions/attributes of GCs, e.g., enhanced security versus other amenities or being a symbol of social status. In this study, we make one of the first attempts to track the pulse of the volatile housing market through monitoring how housing prices of GCs have responded to the COVID-19 pandemic, which has constituted an unexpected exogenous force projecting profound impacts on GCs and housing development more generally in China. In particular, we focus on the price premium generated by the security zone function of GCs, which may have been significantly heightened by the COVID-19 pandemic because of the risk-averse sentiment. During the pandemic, other conditions in existing GCs such as amenities and symbolic values remained largely unchanged; the major changes widely recognized in news reports and social media in Chinese cities have been in the enhanced security measures through stringent access control. If living in GCs brings greater utility for residents in terms of providing extra protection against virus spread by excluding 'suspicious' outsiders during the pandemic, and if the housing market swiftly responds to citizens' growing need for enhanced security, we should be able to observe positive housing price changes within GCs and to quantitatively measure the price premium brought by the security zone effect of GCs.

\section{Data and Methodology}

\subsection{The Case Study of Beijing}

Beijing is the capital city of China and one of the largest and most developed cities in the country. According to the Beijing Municipal Bureau of Statistics, over 21 million residents were living in its administrative area of over 16 thousand square kilometers in 2020. The gross domestic product (GDP) per capita of the Beijing municipality in 2020 amounted to around CNY 164,900, equivalent to about USD 25,500.

We chose Beijing as the study case because this city has experienced the strictest epidemic controls in China (except for the ground zero of Hubei province) and is one of the few Chinese cities that has experienced two waves of the COVID-19 outbreak (see Figure A1). In particular, the Chinese government implemented distinctive strategies in 
these two outbreaks, and it was only in the second outbreak that epidemic controls were mainly organized at the community level [20].

The first outbreak started with the lockdown of Wuhan on 23 January 2020 and ended when the last local infected patient was cured on 8 June in Beijing. The government's major epidemic prevention strategy in the first outbreak was to restrict inbound travels to Beijing and suspend economic activities. Schools and public facilities, such as libraries, did not open until early June. The Beijing government also announced a notice of further strengthening community (village) pandemic prevention and control to require strict access control in residential communities. Those without necessary management facilities were assisted by local officials to impose access controls. Therefore, in the first outbreak period, many local residents significantly reduced their travels within the city and spent most of the time at home. Figure A2 shows that the intensity of internal travel in Beijing did not return to the normal level until early May.

The second outbreak happened on 11 June when new infection cases originated from a large local food market (Xinfadi) supplying $80 \%$ of Beijing's vegetables and meat [40]. Up to the point when Beijing reported no more new cases again for the first time on 7 July, 335 people were infected in this wave. Different from the first outbreak, the government deployed more targeted epidemic controls at the community level in the second wave.

As the government gradually strengthens regular epidemic preventions at the community level, residents' daily activities have been less restricted. However, they have become more cautious about the security of their residential estates. While many estates have regularly checked the residents entering the communities [41], conducting such epidemic controls in those large and open residential communities was reported to be difficult [42]. These two waves of the COVID-19 outbreak in Beijing present a unique opportunity to empirically test how the security zone function of GCs has changed and its influence on the housing market under different pandemic control measures.

\subsection{Data Collection}

\subsubsection{Online Household Survey}

To understand the changing perception of the security zone function of GCs in Beijing during the pandemic, we carried out an online survey in March 2021. The survey was implemented with a professional survey company NetEase, which is also one of the largest internet technology companies in China with over 0.8 billion subscribed users. The online survey invitations were sent to NetEase subscribers using the quota sampling method. To ensure the survey sample represented the general population in the surveyed city, we set a fixed quota for respondents with different housing tenures, and from different age cohorts and districts proportional to the overall population in Beijing. A total of 975 valid questionnaires were collected from residents, with a response rate of $21.4 \%$, which is on par with or even higher than the average response rate for an online survey [43]. The survey was used to collect self-reported information regarding residents' experience with and perception of GCs during the COVID-19 pandemic by asking retrospective questions and to understand their motivations for moving into GCs afterward (see Table A1).

The demographic and socioeconomic profiles of respondents are provided in Table 1, in comparison with the most recent population survey in Beijing. In general, respondents were diverse in terms of their gender, age, education, income level, and location of residence, yet they were less representative of less educated residents (i.e., below high school), female residents, and older residents (i.e., above 60 years old). This suggests that NetEase subscribers tend to be skewed toward the well-educated and younger male population, which is understandable given the widely recognized digital divide. On the positive side, it may better match with our housing data sample, which was mainly drawn from commodity housing in Beijing. Notwithstanding this limitation, we believe that the survey results can offer an important understanding of the general public's changing perception of GCs given the quota sampling strategy. 
Table 1. Summary of Survey Respondents by the Type of Communities.

\begin{tabular}{|c|c|c|c|c|}
\hline & (1) & (2) & (3) & (4) \\
\hline & $\begin{array}{l}\text { All Respondents } \\
\qquad \mathrm{N}=975\end{array}$ & $\begin{array}{c}\text { Respondents from } \\
\text { GCs } \\
N=643\end{array}$ & $\begin{array}{l}\text { Respondents from } \\
\text { Open Communities } \\
\qquad N=333\end{array}$ & $\begin{array}{c}2015 \text { Beijing } 1 \% \\
\text { Population Survey } \\
\text { N }=234,998\end{array}$ \\
\hline Female & $33.43 \%$ & 34.06 & $32.23 \%$ & $47.77 \%$ \\
\hline Age: $18-30$ & $28.94 \%$ & 25.51 & $36.45 \%$ & $29.57 \%$ \\
\hline Age: $31-40$ & $37.33 \%$ & $37.01 \%$ & $37.35 \%$ & $22.39 \%$ \\
\hline Age: $41-60$ & $25.35 \%$ & $28.15 \%$ & $20.18 \%$ & $32.39 \%$ \\
\hline Age: $>61$ & $8.383 \%$ & $9.33 \%$ & $6.02 \%$ & $15.65 \%$ \\
\hline Education: high school and below & $8.483 \%$ & $7.93 \%$ & $8.73 \%$ & $44.09 \%$ \\
\hline Education: college degree & $71.36 \%$ & $71.07 \%$ & $71.99 \%$ & $47.09 \%$ \\
\hline Education: postgraduate & $20.16 \%$ & $21.00 \%$ & $19.28 \%$ & $8.38 \%$ \\
\hline Income: <RMB 5000 & $7.685 \%$ & $7.15 \%$ & $7.53 \%$ & / \\
\hline Income: RMB 5000-10,000 & $36.43 \%$ & $36.70 \%$ & $34.64 \%$ & / \\
\hline Income: RMB 10,000-20,000 & $38.32 \%$ & $38.41 \%$ & $39.76 \%$ & / \\
\hline Income: >RMB 20,000 & $3.994 \%$ & $17.73 \%$ & $18.07 \%$ & / \\
\hline Local Beijing resident & $55.00 \%$ & $58.63 \%$ & $48.19 \%$ & / \\
\hline Rent & $45.11 \%$ & $41.06 \%$ & $51.81 \%$ & $37.41 \%$ \\
\hline
\end{tabular}

Notes: The variables are categorical, and the number indicates the percentage of respondents/population in that category. Income level and local Beijing resident status are not available in the 2015 Beijing $1 \%$ population survey.

Different types of residential communities were well-represented. There were 643 survey respondents (65.9\% of the sample) living in residential communities with gates and walls, and approximately $90 \%$ of them further reported that their communities have at least one type of additional access control, which include gatekeepers/security guards, automatic facial recognition, and smartcard or barcode scanning using smartphones. It is worth noting that there were important similarities between respondents from GCs and those living in open communities. As shown in columns (2) and (3) in Table 1 and Figure 1, they show very similar distributions in terms of gender, education, income, and living district, which are important for their housing choices. Notably, GCs respondents were slightly older than those in open communities, and they were more likely to be local residents and homeowners, i.e., they tend to be relatively better off. Figure 1 shows that the spatial distribution of survey respondents largely resembles the distribution of the total population in Beijing in 2020. This suggests that the online survey can largely reflect Beijing residents' general housing preference and their perception of GCs.

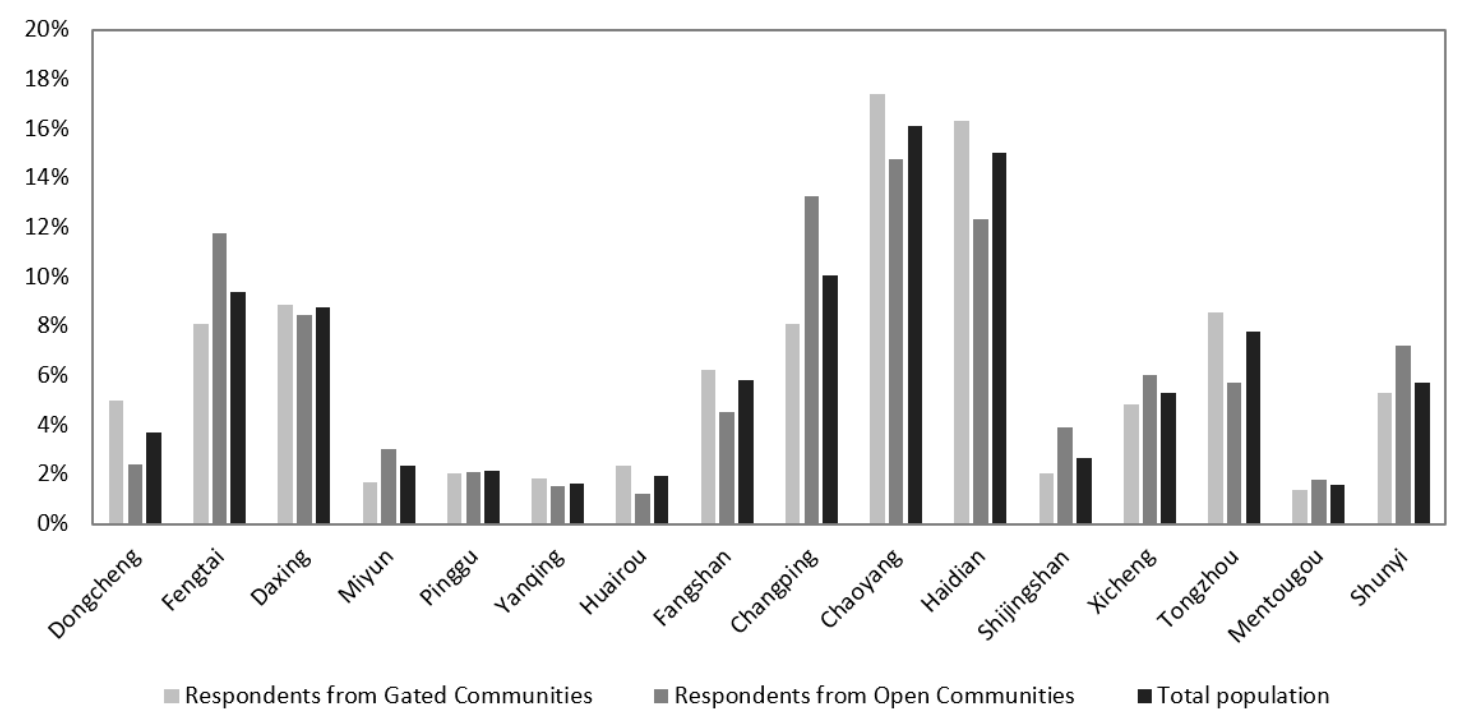

Figure 1. Spatial Distribution of Survey Respondents by the Type of Communities and Total Population. Notes: Total population data is drawn from the 2020 Beijing Municipal Bureau of Statistics. 


\subsubsection{Housing Transaction Data}

We also collected housing transaction data from Lianjia.com (accessed on 20 June 2021) to track the housing market dynamics during the pandemic. Lianjia is the largest real estate agency in Beijing that accounts for approximately $70 \%$ of the market share [44], which thus provides reliable information on the local housing market [45]. Our sample covers residential property transactions in Beijing that occurred between January 2019 and August 2020. Figure 2 presents the map of our study area and the sampled communities. After excluding transactions with incomplete information on housing price or physical property features, we obtained a total sample of 76,465 transactions from 935 residential communities.

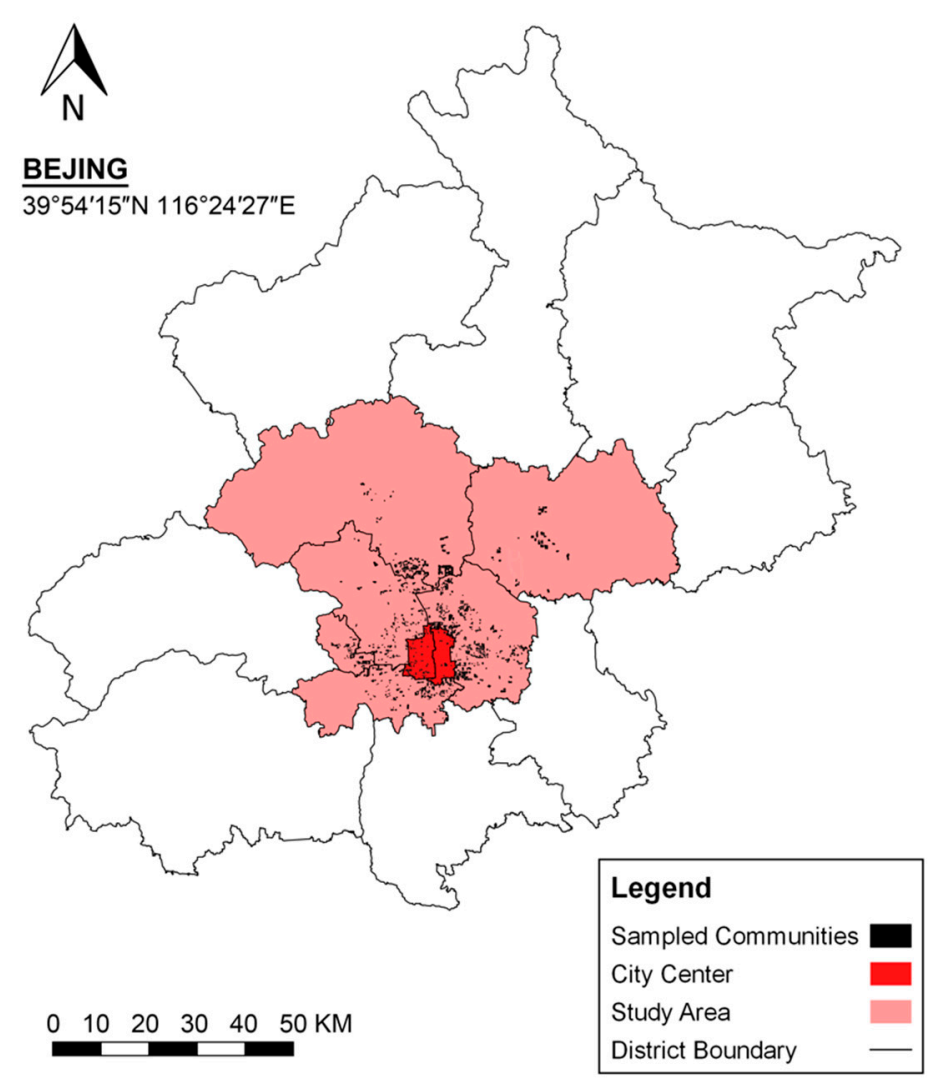

Figure 2. Map of Study Area and Sampled Communities in Beijing.

Referring to Sun [46], we identified GCs using the high-resolution aerial imagery and street views from the Chinese map services, including Baidu (map.baidu.com (accessed on 20 June 2021)), Gaode (amap.com (accessed on 20 June 2021)) and Tencent (map.qq.com (accessed on 20 June 2021)). We measured gatedness by the use of gates for pedestrians and gates for cars. It is more likely for communities with both types of gates to impose access control of outsiders (see examples in Figure A2). Specifically, we defined three categories of gatedness in the order of strictness, denoted as Gated Degree: (1) at least one of visible pedestrian or car entrances from the street view is not gated; (2) all the visible pedestrian and car entrances are gated, but some entrances do not have street views, thereby inhibiting the identification of the gates; (3) all the pedestrian and car entrances are visible and are gated. Thus, a higher Gated Degree denotes a stricter level of access control.

Summary statistics of the transaction data are presented in Table 2, with definitions of the variables reported in Table A2. The average transaction price was RMB 4.978 million. On average, a typical apartment unit had a gross floor area of $81 \mathrm{~m}^{2}, 2$ bedrooms, 1.1 living rooms and 1.2 toilets. Of the units, $63.7 \%$ were accessible by lift, and $24.2 \%$ were facing south. The percentage of the units that had subways stations within $1 \mathrm{~km}$ and bus stops within $500 \mathrm{~m}$ were $54.7 \%$ and $49.5 \%$, respectively. The average number of hospitals, kindergartens, primary and high schools within $2 \mathrm{~km}$ were 7.6, 4.9, 4.4, and 4.1, respectively. 
The average floor area of the community was 109.5 thousand $\mathrm{m}^{2}$. Of the units, $25.9 \%$ were in a community with a green ratio of over $20 \%$, and $19.4 \%$ of them had a plot ratio larger than three. On average, 31.6 potential buyers visited the property before the property was sold at a discount of $3.4 \%$ from the initial listing price.

Table 2. Summary Statistics of Housing Transactions.

\begin{tabular}{|c|c|c|c|c|c|c|}
\hline & (1) & (2) & (3) & (4) & (5) & (6) \\
\hline & $\mathbf{N}$ & Mean & S.D. & Min & Median & Max \\
\hline Price & 76,465 & 4.978 & 2.478 & 0.020 & 4.365 & 43.005 \\
\hline $\log$ (Price) & 76,465 & 6.116 & 0.420 & 0.693 & 6.079 & 8.366 \\
\hline Gated & 75,312 & 0.363 & 0.481 & 0 & 0 & 1 \\
\hline Gated Robust & 75,312 & 0.627 & 0.484 & 0 & 1 & 1 \\
\hline Gated Degree & 75,312 & 1.890 & 0.791 & 1 & 2 & 3 \\
\hline Estate Area & 76,465 & 109.458 & 85.474 & 4.420 & 84.669 & 508.280 \\
\hline $\log$ (Estate Area) & 76,465 & 11.333 & 0.759 & 8.394 & 11.347 & 13.139 \\
\hline Visited Applicants & 75,540 & 31.594 & 41.029 & 0 & 18 & 927 \\
\hline Discount from Listing Price & 73,385 & 0.034 & 0.025 & 0 & 0.029 & 0.134 \\
\hline High Green Ratio & 76,465 & 0.259 & 0.438 & 0 & 0 & 1 \\
\hline High Plot Ratio & 76,465 & 0.194 & 0.396 & 0 & 0 & 1 \\
\hline With Lift & 76,465 & 0.637 & 0.481 & 0 & 1 & 1 \\
\hline Post COVID 1 & 76,465 & 0.187 & 0.390 & 0 & 0 & 1 \\
\hline Post COVID 2 & 76,465 & 0.062 & 0.242 & 0 & 0 & 1 \\
\hline Gross Floor Area & 76,465 & 81.057 & 34.093 & 15.530 & 72.500 & 652.700 \\
\hline No. of Bedrooms & 76,465 & 2.011 & 0.745 & 0 & 2 & 8 \\
\hline No. of Living Rooms & 76,465 & 1.089 & 0.426 & 0 & 1 & 4 \\
\hline No. of Toilets & 76,465 & 1.175 & 0.411 & 0 & 1 & 5 \\
\hline Floor & 76,465 & 4.023 & 1.077 & 1 & 4 & 6 \\
\hline South Orientation & 76,465 & 0.242 & 0.428 & 0 & 0 & 1 \\
\hline Building Age & 76,465 & 19.660 & 8.851 & 1 & 18 & 70 \\
\hline Subway Within $1 \mathrm{~km}$ & 76,465 & 0.547 & 0.498 & 0 & 1 & 1 \\
\hline Bus Within $500 \mathrm{~m}$ & 76,465 & 0.495 & 0.500 & 0 & 0 & 1 \\
\hline Mall Within $1 \mathrm{~km}$ & 76,465 & 0.527 & 0.499 & 0 & 1 & 1 \\
\hline Park Within $1 \mathrm{~km}$ & 76,465 & 0.653 & 0.476 & 0 & 1 & 1 \\
\hline No. of Hospitals in $2 \mathrm{~km}$ & 76,465 & 7.550 & 2.155 & 0 & 8 & 10 \\
\hline No. of Kindergartens in $2 \mathrm{~km}$ & 76,465 & 4.863 & 0.724 & 0 & 5 & 5 \\
\hline No. of High Schools in $2 \mathrm{~km}$ & 76,465 & 4.088 & 1.544 & 0 & 5 & 5 \\
\hline No. of Primary Schools in $2 \mathrm{~km}$ & 76,465 & 4.351 & 1.268 & 0 & 5 & 5 \\
\hline Interior Decoration Quality & 76,465 & 2.752 & 1.355 & 1 & 3 & 4 \\
\hline Holding Period & 76,465 & 1.549 & 0.770 & 1 & 1 & 3 \\
\hline Number of Units in Estate & 76,465 & 2944 & 2072 & 220 & 2319 & 13,077 \\
\hline Total Floors in the Building & 76,465 & 14.639 & 8.315 & 0 & 14 & 36 \\
\hline
\end{tabular}

Approximately $33.4 \%$ of the sampled communities feature a Gated Degree of one and $40.6 \%$ of them a Gated Degree of two. The rest, $26.0 \%$, of the sampled communities have a Gated Degree of three. The share of the sampled communities with a Gated Degree of one (i.e., communities with all entrances confirmed gated) is very close to the ratio of survey respondents from open communities (34.1\%). Figure 3 plots the spatial distribution of the sampled communities by their Gated Degree, reflecting that open and gated communities are rather evenly distributed in different districts. 


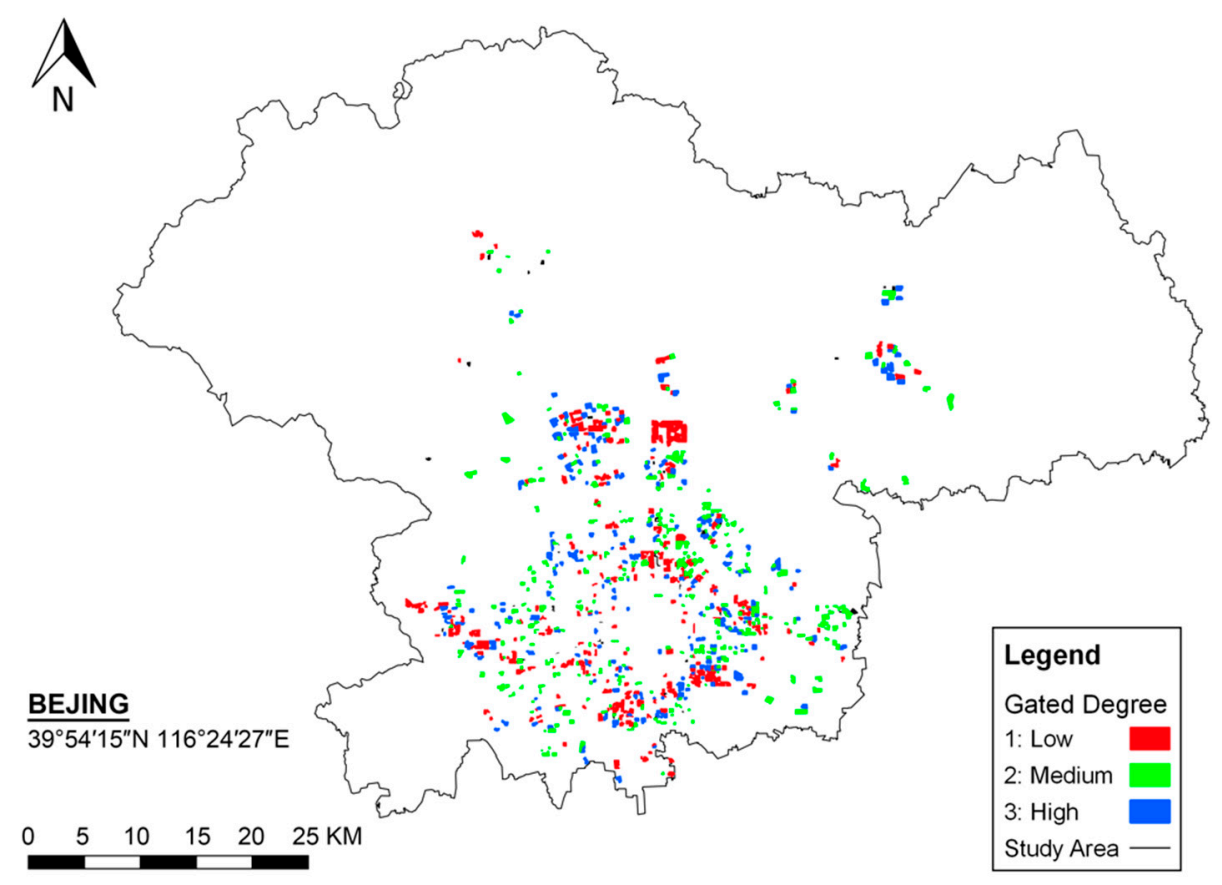

Figure 3. Distribution of the Sampled Community Area by the Gated Degree.

\subsection{Methods for Data Analysis}

For the online survey data, we mainly employed simple descriptive statistics and correlation analysis to unveil changes in people's perception of GCs and motivations for moving into GCs. To process the housing transaction data, we used a standard hedonic price model based on a bundle of physical housing features to identify the housing price dynamics that are commonly applied in housing studies [47].

A multi-period DID strategy was implemented to capture the impact of the COVID-19 pandemic on the housing price difference between gated and open communities. The aim is to provide complementary evidence for changes in people's perception of GCs, which could reflect on the dynamics of the housing market [21,22].

The empirical model is specified as follows

$$
Y_{i, t}=\beta_{1} \text { Gated }_{i} \times \text { Post }_{1 t}+\beta_{2} \text { Gated }_{i} \times \text { Post }_{2 t}+\beta_{3} \text { Gated }_{i}+\lambda^{\prime} X_{i, t}+\omega_{i}+\varphi_{t}+\varepsilon_{i t}
$$

$Y_{i, t}$ is $\log \left(\right.$ Price $\left._{i, t}\right)$, the logarithmic form of the transaction price of unit $i$ at time $t$. Gated $_{i}$ is a dummy variable equal to one if unit $i$ is in a gated community (the treatment group) and equal to zero (the control group) if otherwise. Post ${ }_{1 \mathrm{t}}$ is a dummy variable equal to one if the transaction was made during the first outbreak period in Beijing (i.e., 23 January 2020 to 10 June 2020) and zero if otherwise. Post $2 \mathrm{t}$ is a dummy variable equal to one if the transaction was made during the second outbreak in Beijing (i.e., from 11 June 2020, onwards) and zero if otherwise. $X_{i t}$ is a set of hedonic variables controlling for the physical property features, including area, bedrooms, living rooms, toilets, floors, orientation, building age and total floor number, distance to train station, bus stops, mall, park, hospital, kindergarten, primary school and high school, quality of interior decoration, holding period, and the number of housing units in the estate. $\omega_{i}$ denotes the district fixed effects and $\varphi_{\mathrm{t}}$ denotes the year times month fixed effects. $\varepsilon_{\text {it }}$ is the error term.

In the baseline analysis, we defined the community with a Gated Degree of three as the treatment group (Gated $=1$ ) and with a Gated Degree of one or two as the control group $($ Gated $=0)$. Alternatively, in the robustness test, we defined the estates with a Gated Degree of two or three as the treatment group (Gated Robust $=1$ ) and the estates with a Gated Degree of one as the control group (Gated Robust $=0$ ). Moreover, we directly used the ordinal variable Gated Degree as the explanatory variable in an additional robustness test. 
The coefficients $\beta_{1}$ and $\beta_{2}$ estimate the changes in the price difference between gated and open communities due to the pandemic. The coefficient $\beta_{3}$ represents the price difference between gated and open communities before the pandemic. In other words, it captures the ex-ante factors other than COVID-19 that drive the price difference between gated and open communities, which include the difference in the quality of amenities and social status of residents inside. Provided that the demand for these functions of GCs remain unchanged within a short period, $\beta_{1}$ and $\beta_{2}$ should represent the impact of the perception changes of GCs' security zone function on housing prices during the two COVID-19 outbreaks.

\section{Changing Perception of GCs}

An increased popularity of GCs owing to the pandemic-induced safety concern is evidenced by the online survey results. First, it is shown that GCs are more likely to implement strict pandemic controls and the security function has been widely recognized by respondents in Beijing. According to the respondents, 80.0\% of those living in GCs reported the existence of a special entrance permit with which only residents or people with special permission can access the community during the pandemic, while the figure was only $63.6 \%$ in open communities. Given the lack of official statistics to testify to the effectiveness of gating in containing virus' spread, we rely on the perceived benefits reported by residents. Specifically, we asked respondents to evaluate the effectiveness of the main access control measures adopted in their GCs during the pandemic. Over $90 \%$ of the respondents believe that community access controls helped to contain the spread of coronavirus. Smartcard or barcode scanning using a smartphone, with which only residents or people with special permission can access the community during the pandemic, is perceived as the most effective measure, which is favored by $79.3 \%$ of the respondents. What followed is the use of automatic facial recognition (agreed by $70.4 \%$ ) and gatekeepers/security guards (selected by $68.4 \%$ ).

Second, while GCs have been popular among Chinese residents in the past two decades owing to the pursuit of security, prestige, and lifestyle, the COVID-19 pandemic has further pushed up GCs patronage. Considering GCs' effectiveness in excluding unwanted outsiders to contain the virus spread, $80.7 \%$ of existing GCs residents prefer GCs over open communities. Meanwhile, $70.2 \%$ of these GCs residents choose to stay in GCs to mitigate their fear of coronavirus. Possibly due to the negative experience during the pandemic, over $70 \%$ of respondents living in open communities prefer GCs, either for their effectiveness of pandemic control or for mitigating the fear of coronavirus. Moreover, a positive correlation between these two pandemic-related motives and the willingness to pay a price premium for living in GCs after the pandemic was discovered. Table 3 presents the results of the Pearson correlation tests. Among respondents living in open communities, the correlation between the willingness to pay a premium and the preference for GCs due to the effectiveness of pandemic control is 0.26 and among existing GCs residents, it is 0.2. The correlation between the willingness to pay a premium and the preference for GCs for mitigating the fear of the pandemic is 0.17 for open-community residents and 0.18 for GCs residents. That is to say, the pandemic-induced security concern may translate into a housing price premium.

Table 3. Pearson correlation tests.

(1)

Respondents from GCs
(2)

Respondents from Open Communities

The preference for GCS due to:

The effectiveness of epidemic control

The willingness to pay a premium for GCs

Mitigating the fear for the pandemic
$0.20^{* * *}$
$0.26^{* * *}$
$0.18^{* * *}$
$0.17^{* * *}$ 
Hence, our survey results provide answers to our first research question by suggesting that the security zone function of GCs has been heightened and widely recognised and the security concern has become an important motive for residents choosing GCs over open communities after the pandemic. Nonetheless, it is noteworthy that GCs' effectiveness in pandemic control is based on residents' subjective evaluation, which has not been supported by the evidence of the actual infection rate in GCs versus open communities. The next section will examine how this changing perception of GCs' security zone function affected the housing market dynamic during the two pandemic outbreaks in Beijing to provide answers to our second research question.

\section{Housing Market Dynamics Affected by the Changing Perception of GCs}

\subsection{Housing Price Premium}

Table 4 reports the estimation results of Equation (1), using log (Price $\left.{ }_{i, t}\right)$ as the dependent variable. In column (1), the treatment and control groups are classified by our main identification of GCs (i.e., Gated). Before the COVID-19 pandemic, units in the GCs were sold at a premium of $3.72 \%$ in comparison with units in open communities, controlling for other housing features. This result aligns with findings documented in the Western literature that the benefits associated with the GCs increase the property price. During the first outbreak period, no significant change was observed in this housing price premium of GCs over open communities. However, after the second outbreak, the prices of units in GCs become higher than those in open communities by an additional $1.99 \%$, making a total price premium amounting to $5.71 \%$.

Table 4. Baseline Regression Results on Housing Prices.

\begin{tabular}{|c|c|c|c|}
\hline & (1) & (2) & (3) \\
\hline & & Log (Price) & \\
\hline Gated $\times$ Post COVID 1 & $\begin{array}{l}-0.0031 \\
(0.0037)\end{array}$ & & \\
\hline Gated $\times$ Post COVID 2 & $\begin{array}{c}0.0199 * * * \\
(0.0059)\end{array}$ & & \\
\hline Gated & $\begin{array}{c}0.0372 * * * \\
(0.0018)\end{array}$ & & \\
\hline Gated Robust $\times$ Post COVID 1 & & $\begin{array}{l}-0.0006 \\
(0.0034)\end{array}$ & \\
\hline Gated Robust $\times$ Post COVID 2 & & $\begin{array}{c}0.0186^{* * *} \\
(0.0057)\end{array}$ & \\
\hline Gated Robust & & $\begin{array}{c}0.0667^{* * *} \\
(0.0017)\end{array}$ & \\
\hline Gated Degree $\times$ Post COVID 1 & & & $\begin{array}{c}0.0009 \\
(0.0021)\end{array}$ \\
\hline Gated Degree $\times$ Post COVID 2 & & & $\begin{array}{l}0.0056^{*} \\
(0.0034)\end{array}$ \\
\hline Gated Degree & & & $\begin{array}{c}0.0307^{* * *} \\
(0.0010)\end{array}$ \\
\hline Constant & $\begin{array}{c}4.6444^{* * *} \\
(0.0313)\end{array}$ & $\begin{array}{c}4.5932 * * * \\
(0.0310)\end{array}$ & $\begin{array}{c}4.6357^{* * * *} \\
(0.0309)\end{array}$ \\
\hline Physical Property Features & $\mathrm{Y}$ & $\mathrm{Y}$ & $\mathrm{Y}$ \\
\hline District Fixed Effects & $\mathrm{Y}$ & $\mathrm{Y}$ & $\mathrm{Y}$ \\
\hline Year $\times$ Month Fixed Effects & $\mathrm{Y}$ & Y & Y \\
\hline Observations & 75,312 & 75,312 & 75,312 \\
\hline R-squared & 0.809 & 0.812 & 0.810 \\
\hline
\end{tabular}

Notes: Heteroskedasticity adjusted robust standard errors are reported in parentheses. ${ }^{* * *}$, and ${ }^{*}$ denotes statistical significance at the $1 \%$, and $10 \%$ level, respectively.

Then, we tested the robustness of this finding by using alternative identifications of GCs (i.e., Gated Robust and Gated Degree), and the estimation results are reported in Columns (2) and (3) of Table 4. We found that after the second outbreak, the housing price 
of units in GCs increased by $1.86 \%$ more than units in open communities (Column (2)). If the degree of gatedness increases by 1 , then the housing price after the second outbreak increases by $0.56 \%$ (Column (3)). However, we did not find a significant impact during the first outbreak, showing that our main finding remains intact. Lastly, a parallel pre-trend is the key assumption in a DID model, and we verified this assumption by showing that no statistically significant change existed in the price premium of GCs before the COVID-19 outbreaks (details in Table A3).

Thus, our findings imply that residents became more willing to pay a larger price premium for units in GCs due to the COVID-19 outbreak. This case is specifically true after the second outbreak because the community-centric pandemic controls were implemented only after the second outbreak [19], which led residents to care more about the community's gatedness and security. We did not observe a significant impact during the first outbreak because most residents were more radically restricted in their own communities and the lockdown policies were generally uniform in the entire city. Thus, residents were less likely to be concerned about the gatedness of individual communities when the entire city was locked down. In this compulsory locked down period, they would have been concerned more about the housing quality inside the communities. This notion is supported as we found that in the first outbreak, factors inside the communities, such as a higher green ratio and a lower plot ratio, had a stronger impact on housing prices (detailed analysis provided in Table A4). On the contrary, as China's President Xi has proclaimed that community-level pandemic controls should be 'regularized' for the coming years, the 'security zone' effect of GCs on housing prices in the second outbreak is, thus, expected to be prolonged in the years to come.

One major limitation of the study is that, although we have demonstrated an increasing housing preference for GCs over open communities after the COVID-19 pandemic using the DID model, and shown that the security concern is a driver for the demand using the survey data, it is possible that other features of gated communities may also account for the increasing post-pandemic demand for GCs. For instance, residents may prefer better amenities after the pandemic, which could concurrently spur the price of GCs together with the security concern. To eliminate this alternative explanation, we constructed an indirect measurement of the luxury estate as the proxy for the unobserved community amenities. Specifically, we defined the estates with the top $10 \%$ largest average unit size in Beijing as the luxury estate because the luxury estates usually offer larger units as well as better amenities. We found that the price premium of luxury estates did not change due to COVID-19 (details in Table A4), which implies that flight-to-amenity is unlikely to be the cause of increasing housing demand for GGs. Nevertheless, we acknowledge that while we have investigated and disproved of the impact of green space, plot ratio, use of a lift, and luxury estates, we could not fully rule out the impact of all other unobserved amenities due to data limitation.

\subsection{Number of Visited Applicants and Discount from Listing Prices}

The above results have suggested that the housing prices in GCs grew higher after the pandemic compared with those of open communities as residents were more concerned with security issues at the community level, and GCs, thus, have become more popular. To verify this finding, we conducted two additional tests. Specifically, we have shown that GCs became more popular than open communities after the pandemic as more potential buyers visited the listed units in GCs, and the corresponding discount in transaction prices compared with listed prices significantly decreased in GCs.

If the price of units in GCs grew higher due to the popularity of GCs after the pandemic, it is hypothesized that more potential buyers would visit these units and the final transaction price would be closer to the initial listing price. To test this hypothesis, we first replaced the dependent variable in Equation (1) with the number of visited applicants. The estimation results are reported in the first three columns of Table 5. In columns (1) and (2), we use Gated and Gated Robust as independent variables, respectively. We found that 
units in GCs had two more visits than units in open communities on average due to the first outbreak and over four more visits due to the second outbreak. In column (3), we use Gated Degree as the independent variable, and a one-degree increase in the gated level leads to 2.04 additional visits in the second outbreak.

Table 5. Regression Results on Number of Visited Applicants and Listing Price Discounts.

\begin{tabular}{|c|c|c|c|c|c|c|}
\hline & (1) & (2) & (3) & (4) & (5) & (6) \\
\hline & \multicolumn{3}{|c|}{ Number of Visited Applicants } & \multicolumn{3}{|c|}{ Discounts from Listing Price } \\
\hline Gated $\times$ Post COVID 1 & $\begin{array}{l}2.2515^{* * * *} \\
(0.8728)\end{array}$ & & & $\begin{aligned}-0.0016^{* * *} & (0.0004)\end{aligned}$ & & \\
\hline Gated $\times$ Post COVID 2 & $\begin{array}{l}4.2466^{* * * *} \\
(1.5716)\end{array}$ & & & $\begin{aligned}-0.0025^{* * *} & (0.0006)\end{aligned}$ & & \\
\hline Gated & $\begin{array}{l}1.1114^{* * *} \\
(0.3785)\end{array}$ & & & $\begin{array}{c}0.0009^{* * * *} \\
(0.0003)\end{array}$ & & \\
\hline Gated Robust $\times$ Post COVID 1 & & $\begin{array}{l}2.0981^{* * * *} \\
(0.7990)\end{array}$ & & & $\begin{aligned}- & 0.0016^{* * *} \\
& (0.0004)\end{aligned}$ & \\
\hline Gated Robust $\times$ Post COVID 2 & & $\begin{array}{l}4.9158^{* * * *} \\
(1.3902)\end{array}$ & & & $\begin{aligned}-0.0026^{* * *} & (0.0006)\end{aligned}$ & \\
\hline Gated Robust & & $\begin{array}{l}0.6477 * \\
(0.3590)\end{array}$ & & & $\begin{array}{c}0.0012^{* * *} \\
(0.0002)\end{array}$ & \\
\hline Gated Degree $\times$ Post COVID 1 & & & $\begin{array}{c}0.7439 \\
(0.4745)\end{array}$ & & & $\begin{array}{l}-0.0006^{* *} \\
(0.0002)\end{array}$ \\
\hline Gated Degree $\times$ Post COVID 2 & & & $\begin{array}{c}2.0415^{* *} \\
(0.8406)\end{array}$ & & & $\begin{aligned}- & 0.0010^{* * * *} \\
& (0.0004)\end{aligned}$ \\
\hline Gated Degree & & & $\begin{array}{c}0.0470 \\
(0.2054)\end{array}$ & & & $\begin{array}{l}0.0005^{* * *} \\
(0.0001)\end{array}$ \\
\hline Constant & $\begin{array}{l}4.6444^{* * * *} \\
(0.0313)\end{array}$ & $\begin{array}{l}4.5932 * * * \\
(0.0310)\end{array}$ & $\begin{array}{l}4.6357^{* * *} \\
(0.0309)\end{array}$ & $\begin{array}{l}0.0457^{* * * *} \\
(0.0026)\end{array}$ & $\begin{array}{l}0.0453^{* * *} \\
(0.0026)\end{array}$ & $\begin{array}{l}0.0458^{* * *} \\
(0.0026)\end{array}$ \\
\hline Physical Property Features & $\mathrm{Y}$ & $\mathrm{Y}$ & $\mathrm{Y}$ & Y & $\mathrm{Y}$ & $\mathrm{Y}$ \\
\hline District Fixed Effects & $\mathrm{Y}$ & $\mathrm{Y}$ & $\mathrm{Y}$ & Y & $\mathrm{Y}$ & Y \\
\hline Year $\times$ Month Fixed Effects & $\mathrm{Y}$ & $\mathrm{Y}$ & Y & $\mathrm{Y}$ & Y & $\mathrm{Y}$ \\
\hline Observations & 74,404 & 74,404 & 74,404 & 72,299 & 72,299 & 72,299 \\
\hline R-squared & 0.086 & 0.086 & 0.086 & 0.102 & 0.102 & 0.102 \\
\hline
\end{tabular}

Notes: Heteroskedasticity adjusted robust standard errors are reported in parentheses. ${ }^{* * *}, * *$, and ${ }^{*}$ denotes statistical significance at the $1 \%, 5 \%$, and $10 \%$ level, respectively.

Similarly, we used the discount in the transaction price from the listing price as the dependent variable in Equation (1), with results reported in the last three columns of Table 5. We found that, during the first outbreak, the discount from the listing price for units in GCs was $0.16 \%$ lower than that for units in open communities. This reduction in discount became $0.25-0.26 \%$ in the second outbreak. A one-degree increase in gated degree resulted in a smaller discount from the listing price by $0.06 \%$ and $0.10 \%$ in the first and second outbreaks, respectively.

Taken together, the empirical evidence suggests that housing units in GCs became more popular compared with open communities in Beijing after the pandemic, specifically after its second outbreak.

\section{Conclusions and Discussion}

GCs in China present some distinct features, not only in terms of the scale, pervasiveness, and historical and cultural roots but also in the decisive role of the state and the perceptions of residents. Researchers need to investigate beyond the endogenous configuration of the built form and probe into residents' urban experience under different exogenous forces to develop a dynamic and nuanced understanding of GCs in China and other contexts.

This research perceives the COVID-19 pandemic as a unique opportunity to examine the changes in people's perception of GCs in the face of an unexpected exogenous force and its influence on the housing market dynamic. Before the pandemic, Chinese GCs 
with varying degrees of affordability were mainly regarded as an efficient way of housing and related services provision, and segregation and exclusion were less of a concern of the public $[9,26]$. This research shows that an enhanced security zone function has been rediscovered in China's GCs after the pandemic. The COVID-19 outbreak has heightened the sense of fear and insecurity in contemporary Chinese cities that feature high mobilities and uncertainties, which foregrounds the importance of safety in housing choices. GCs, thus, have gained increasing popularity for their perceived effectiveness in access control and their exclusion of 'suspicious' and 'threatening' outsiders. This notion is indirectly evidenced by a greater preference for GCs after the pandemic, as reflected in higher prices, more potential buyer visits, and smaller transaction price discounts from the initial listing price. On the generalizability of our findings, it should be noted that our analysis is essentially city- and time-specific, subject to possible data biases. Our study focuses on Beijing only, which is unique among Chinese cities due to its political and economic status. The empirical findings of GCs in Beijing during the pandemic do not necessarily apply to other Chinese cities, for which further studies are in need.

This finding on the heightened security function of GCs is nontrivial for three reasons. First, from the perspective of pandemic control, our results indicate that it is essential to ensure adequate security measures of residential communities during severe public health emergences. Second, the enhanced security function of gating not only reflects residents demand but also sends out a strong and possibly misleading signal to real estate developers to increase the development of new GCs and the tightening of gating measures and access control. As a result, the COVID-19 pandemic may transform the relatively accessible and permeable features of GCs in China and make it a more negative and segregated urban form as documented in Western countries. Third, the elevated housing price of GCs will also worsen housing affordability and inequalities. Hence, certain social groups, specifically rural-urban migrants and low- to middle-income renters, are expected to be further excluded and marginalized, or even indirectly evicted from first-tier cities. This is particularly alarming for post-pandemic cities that will most likely suffer from a long-term economic downturn and a greater degree of inequalities.

These potential consequences of the changing functions and perceptions of GCs urge us to rethink the meaning and socio-spatial implications of GCs in post-pandemic Chinese cities. As GCs becoming the dominant type of urban residence, it is important for policymakers and urban planners to rethink the balance between the importance of enhancing security during severe public health emergences and the need for accessible and permeable residential neighborhoods in post-pandemic cities. This study also sheds new light on our understanding of GCs' impact on housing market dynamics by foregrounding the importance of exogenous forces, for example, public health emergencies in this case, the significant yet complex and even paradoxical role played by state regulations, e.g., the community-level pandemic control measures, and the necessity for a dynamic examination of the evolving housing market dynamic and possible measures to mitigate housing inequality and segregation.

Findings from this research can also inform spatial planning policies to achieve a more accessible, inclusive, and safe urban built environment in China. Previous advocacy and discussion on ungating the Chinese city have overlooked GC residents' major concerns and perceptions, especially those concerning property values and community safety. Most of those advocacies were, thus, unmaterialized. Our research findings allude to some concrete and feasible measures, e.g., enhancing security measures and risk-tracking and prevention measures at the neighborhood level, which can be introduced in future spatial planning policies to balance residents' demands for a safe living environment and an overall urban planning goal of achieving a more accessible and inclusive city for all urban dwellers.

Author Contributions: Conceptualization, L.L., W.X.W. and S.H.; Data curation, L.L., W.X.W. and S.H.; Formal analysis, L.L. and W.X.W.; Funding acquisition, L.L. and S.H.; Investigation, S.H.; Methodology, L.L. and W.X.W.; Project administration, L.L.; Resources, S.H.; Software, W.X.W.; Supervision, S.H.; Validation, L.L. and W.X.W.; Visualization, W.X.W.; Writing一original draft, L.L. 
and W.X.W.; Writing - review and editing, S.H. All authors have read and agreed to the published version of the manuscript.

Funding: This research was funded by the National Natural Science Foundation of China, grant number 41871165X and Lincoln Institute of Land Policy China Program International Fellowship.

Data Availability Statement: The data used in this paper mainly come from Lianjia.com (accessed on 20 June 2021).

Acknowledgments: We appreciate the comments from Chris Webster and other seminar participants at the $2021 \mathrm{HKU}$-Cambridge Joint Seminar Series.

Conflicts of Interest: The authors declare no conflict of interest.

\section{Appendix A}

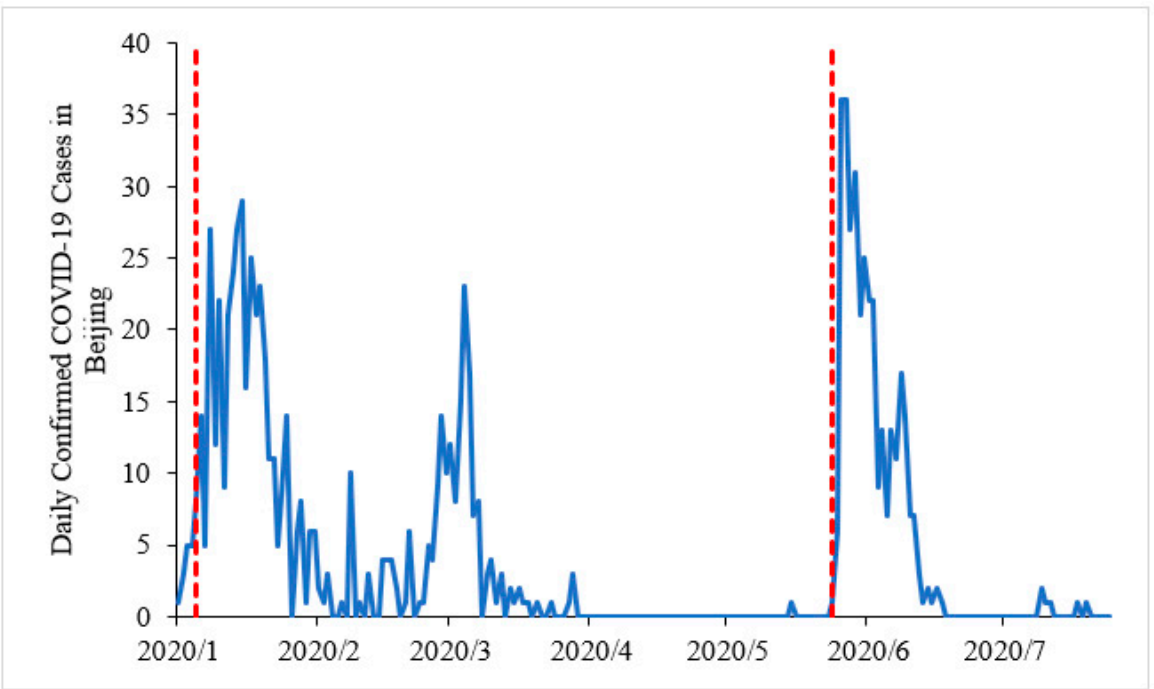

Figure A1. Daily Confirmed COVID-19 Cases in Beijing. Notes: The data is from Johns Hopkins Coronavirus Resource Center.

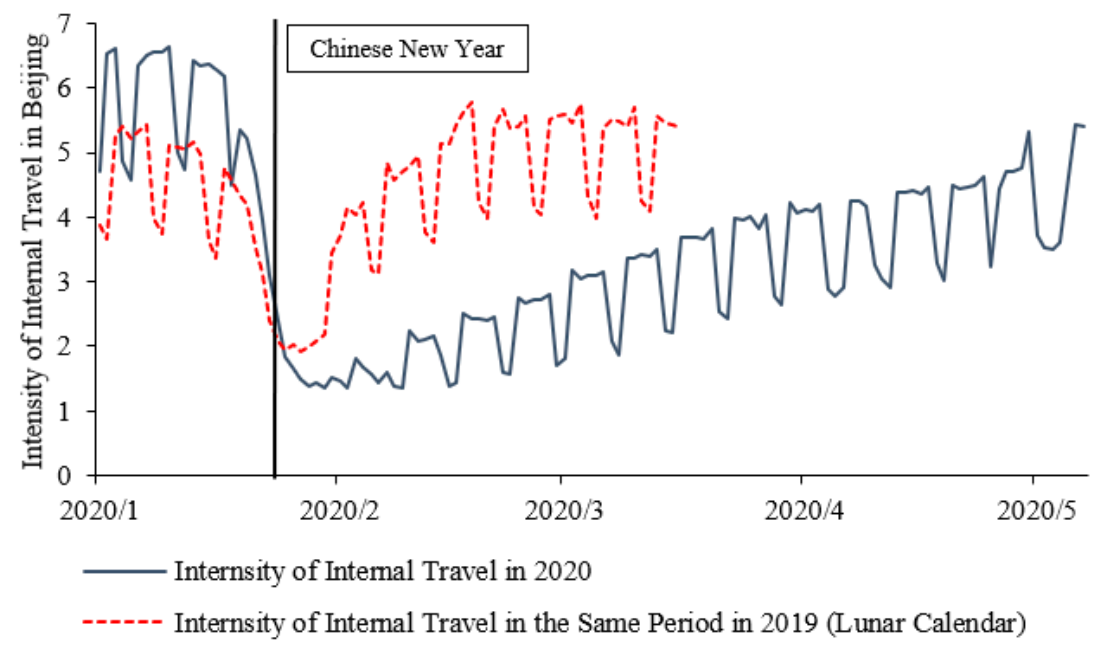

Figure A2. The Intensity of Internal Travel in Beijing. Notes: The data is from Baidu Qianxi Mobility Dataset. The intensity of internal travel in an index measuring the total number of travelling residents in a city divided by the residential population. 


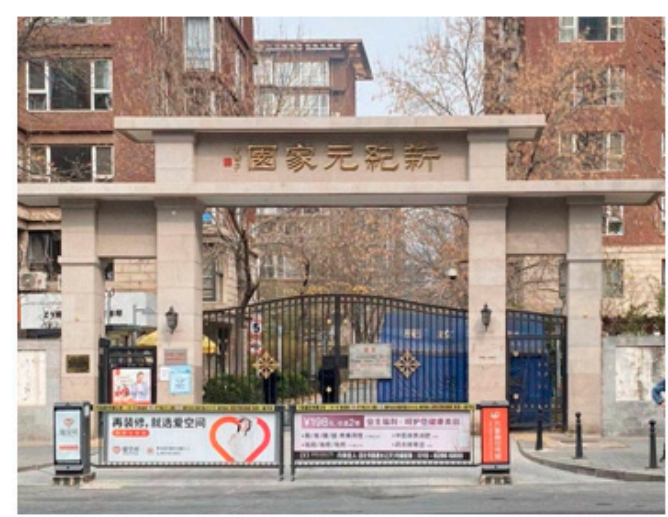

a

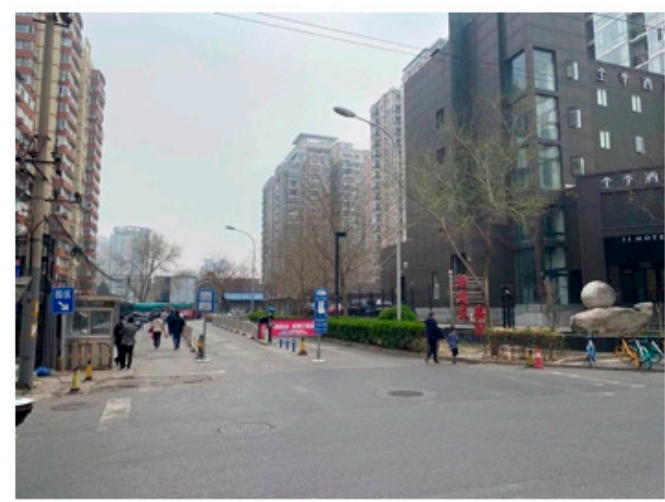

C

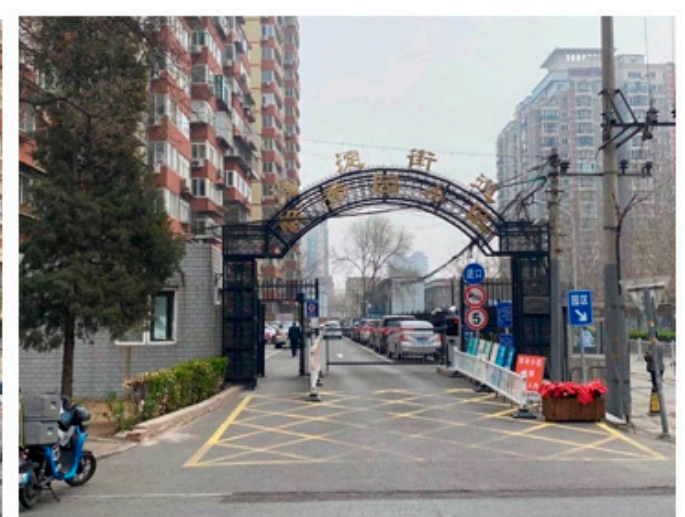

b

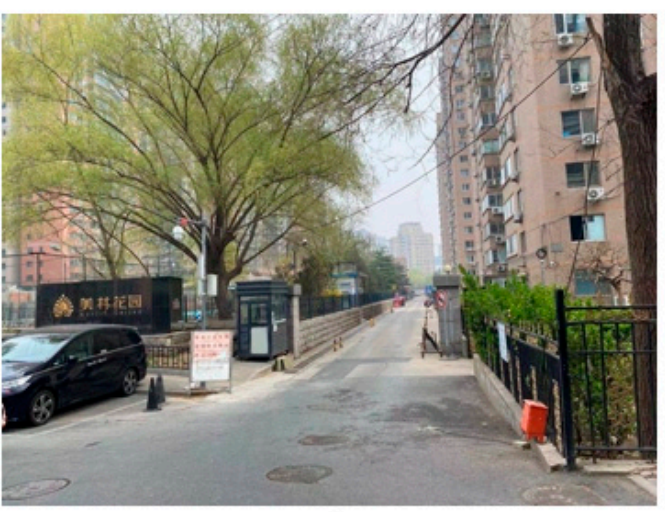

d

Figure A3. Examples of Gated Communities and Open Communities. (a) Gated Communities: Xingjiyuan Estate; (b) Gated Communities: Yixiuyuan Estate; (c) Open Communities: Xingjiyuan Estate; (d) Open Communities: Yixiuyuan Estate.

\section{Appendix B}

Table A1. Key Survey Questions.

Q1: Does your residential community have the following gated facilities?
a. Gates and walls: Yes/No
b. Gatekeepers/security guards: Yes/No
c. Smartcard or barcode scanning using smartphone at the entrance: Yes/No
d. Automatic facial recognition: Yes/No

Q2: Does your residential community require "entrance permit" during the pandemic?
a. Yes
b. No

Q3: Do you think the following community access control measures are useful for preventing and controlling the pandemic?
a. Gates and walls: Yes/No
b. Gatekeepers/security guards: Yes/No
c. Smartcard or barcode scanning using smartphone at the entrance: Yes/No
d. Automatic facial recognition: Yes/No

Q4: Do you agree the following argument: (using 5-point Likert scale)

(1) "I prefer to live in a gated community because of its better pandemic prevention and control measures and capabilities"

(2) "I prefer to live in a gated community to mitigate my fear for coronavirus" 
Table A1. Cont.

Q5: Are you willing to pay more for living in a gated community than in an open community, holding other factors constant?
a. Yes
b. No

Table A2. Definition of Variables.

\begin{tabular}{ll}
\hline \multicolumn{1}{c}{ Variables } & \multicolumn{1}{c}{ Definition } \\
\hline Price & The transaction price of the property in the unit of million RMB. \\
\hline Gated & $\begin{array}{l}\text { A dummy variable equal to } 1 \text { if all the pedestrian entrances are visible from the map and are } \\
\text { with access controls, zero otherwise. }\end{array}$
\end{tabular}

A dummy variable equal to 1 if all the visible pedestrian entrances from the map are with

Gated Robust access controls, although some entrances do not have street views which inhibits the identification of the access control. Otherwise, it equals zero.

A continuous variable equal to 3 if all the pedestrian entrances are visible from the map and

Gated Degree are with access controls, and 2 if all the visible pedestrian entrances from the map are with access controls, although some entrances do not have street views. Otherwise, it equals one.

\begin{tabular}{ll} 
Estate Area & The estate's total floor area in the unit of thousand squared meters. \\
\hline Visited Applicants & Total number of visited applicants (i.e., potential buyers) between listing and final transaction. \\
\hline Discount from Listing Price & $\begin{array}{l}\text { The discount in the final transaction price from the listing price, calculated as 1-(transaction } \\
\text { price/listing price). }\end{array}$
\end{tabular}

\begin{tabular}{ll} 
High Green Ratio & A dummy variable equal to 1 if the green ratio of the estate is larger than $20 \%$, zero otherwise. \\
\hline High Plot Ratio & A dummy variable equal to 1 if the plot ratio of the estate is larger than 3, zero otherwise. \\
\hline $\begin{array}{l}\text { Luxury Estate } \\
\text { A dummy variable equal to } 1 \text { if the average unit size in an estate is in the top } 10 \% \text { of the } \\
\text { average unit size of all estates in Beijing, zero otherwise. }\end{array}$
\end{tabular}

With Lift A dummy variable equal to 1 if the building has a lift, zero otherwise.

\section{Post COVID 1}

A dummy variable equal to 1 if the transaction is after 22 January 2020 (i.e., the lockdown of Wuhan) and before 11 June 2020 (i.e., the outbreak in the Xinfadi Seafood Market), zero otherwise.

\section{Post COVID 2}

A dummy variable equal to 1 if the transaction is after 11 June 2020 (i.e., the outbreak in the Xinfadi Seafood Market), zero otherwise.

\begin{tabular}{ll}
\hline Gross Floor Area & Total gross floor area of the unit. \\
\hline No. of Bedrooms & Number of bedrooms in the unit. \\
\hline No. of Living Rooms & Number of living rooms in the unit. \\
\hline No. of Toilets & Number of toilets in the unit. \\
\hline Floor & $\begin{array}{l}\text { A categorical variable indicating the range of the unit floor: } 0=\text { Underground Level; } 1=\text { First } \\
\text { Level; } 2=\text { Low Level; } 3=\text { Mid-Level; } 4=\text { High Level; } 5=\text { Top Level }\end{array}$ \\
\hline South Orientation & A dummy variable equal to 1 if the unit is facing south, zero otherwise. \\
\hline Building Age & Age of the building, calculated as the transaction year minus the building completion year. \\
\hline Subway Within $1 \mathrm{~km}$ & $\begin{array}{l}\text { A dummy variable equal to } 1 \text { if there is at least one subway station within } 1 \mathrm{~km} \text { from the unit, } \\
\text { zero otherwise. }\end{array}$ \\
\hline
\end{tabular}

Bus Within $500 \mathrm{~m}$ A dummy variable equal to 1 if there is at least one bus stop within $500 \mathrm{~m}$ from the unit, zero otherwise.

Mall Within $1 \mathrm{~km}$ A dummy variable equal to 1 if there is at least one shopping mall within $1 \mathrm{~km}$ from the unit, zero otherwise.

Park Within $1 \mathrm{~km}$ A dummy variable equal to 1 if there is at least one park within $1 \mathrm{~km}$ from the unit, zero otherwise. 
Table A2. Cont.

\begin{tabular}{ll}
\hline \multicolumn{1}{c}{ Variables } & \multicolumn{1}{c}{ Definition } \\
\hline No. of Kindergartens in $2 \mathrm{~km}$ & The number of kindergartens within $2 \mathrm{~km}$ from the unit. \\
\hline No. of High Schools in $2 \mathrm{~km}$ & The number of high schools within $2 \mathrm{~km}$ from the unit. \\
\hline No. of Primary Schools in $2 \mathrm{~km}$ & The number of primary schools within $2 \mathrm{~km}$ from the unit. \\
\hline Interior Decoration Quality & $\begin{array}{l}\text { A categorical variable denoting the interior decoration quality: } 0=\text { Others; } 1=\text { No decoration; } \\
2=\text { Decorated; } 3=\text { Well decorated. }\end{array}$ \\
\hline Holding Period & $\begin{array}{l}\text { A categorical variable denoting the holding period: } 0=\text { Less than two years; } 1=\text { Two to five } \\
\text { years; } 2=\text { More than five years. }\end{array}$ \\
\hline Number of Units in Estate & Total number of units in the estate. \\
\hline Total Floors in the Building & Total number of floors in the building. \\
\hline
\end{tabular}

Table A3. Pre-Trend Test for the Multi-Period DID Model.

(1)

(2)

(3)

\section{Log (Price)}

$\begin{array}{cc}\text { Gated } \times \text { Pre-Trend Period } & 0.0039 \\ & (0.0044) \\ \text { Gated } \times \text { Post COVID 1 } & -0.0025 \\ \text { Gated } \times \text { Post COVID } 2 & (0.0038) \\ \text { Gated } & 0.0205^{* * *} \\ & (0.0060) \\ & 0.0366^{* * *}\end{array}$

Gated Robust $\times$ Pre-Trend Period

(0.0020)

Gated Robust $\times$ Post COVID 1

$(0.0038)$

0.0001

(0.0035)

Gated Robust $\times$ Post COVID 2

$0.0193^{* * *}$

(0.0058)

Gated Robust

(0.0018)

Gated Degree $\times$ Pre-Trend Period

Gated Degree $\times$ Post COVID 1

0.0012

Gated Degree $\times$ Post COVID 2

Gated Degree

\section{Constant}

Physical Property Features

District Fixed Effects

Year $\times$ Month Fixed Effects

Observations

R-squared

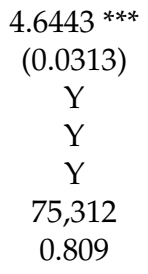

$0.0304 * * *$

(0.0010)

$4.6357^{* * *}$

(0.0309)

$(0.0310)$
Y
Y
Y
75,312
0.812

$\mathrm{Y}$

Y

$\mathrm{Y}$

75,312

0.810

Notes: Pre-Trend Period is a dummy variable denoting if the transaction is between 22 November 2019 and 21 January 2020 (i.e., two months before the lock down of Wuhan). Heteroskedasticity adjusted robust standard errors are reported in parentheses. ${ }^{* * *}$, and ${ }^{*}$ denotes statistical significance at the $1 \%$, and $10 \%$ level, respectively. 
Table A4. Other Factors with Transient Effect.

\begin{tabular}{|c|c|c|c|c|}
\hline & (1) & (2) & (3) & (4) \\
\hline & \multicolumn{4}{|c|}{ Log (Price) } \\
\hline High Green Ratio × Post COVID 1 & $\begin{array}{l}-0.0025 \\
(0.0041)\end{array}$ & & & \\
\hline High Green Ratio × Post COVID 2 & $\begin{array}{c}0.0088 \\
(0.0067)\end{array}$ & & & \\
\hline High Green Ratio & $\begin{array}{c}0.0062^{* * *} \\
(0.0021)\end{array}$ & & & \\
\hline High Plot Ratio $\times$ Post COVID 1 & & $\begin{array}{l}-0.0110 * * * \\
(0.0043)\end{array}$ & & \\
\hline High Plot Ratio $\times$ Post COVID 2 & & $\begin{array}{l}-0.0053 \\
(0.0070)\end{array}$ & & \\
\hline High Plot Ratio & & $\begin{array}{l}-0.0250 * * * \\
(0.0022)\end{array}$ & & \\
\hline With Lift $\times$ Post COVID 1 & & & $\begin{array}{l}-0.0105^{* * *} \\
(0.0035)\end{array}$ & \\
\hline With Lift $\times$ Post COVID 2 & & & $\begin{array}{c}0.0058 \\
(0.0059)\end{array}$ & \\
\hline With Lift & & & $\begin{array}{l}0.0737^{* * *} \\
(0.0026)\end{array}$ & \\
\hline Luxury Estate $\times$ Post COVID 1 & & & & $\begin{array}{c}0.0040 \\
(0.0073)\end{array}$ \\
\hline Luxury Estate $\times$ Post COVID 2 & & & & $\begin{array}{c}0.0010 \\
(0.0107)\end{array}$ \\
\hline Luxury Estate & & & & $\begin{array}{c}0.0603 * * * \\
(0.0037)\end{array}$ \\
\hline Constant & $\begin{array}{c}4.6665^{* * *} \\
(0.0322)\end{array}$ & $\begin{array}{l}4.6687^{* * *} \\
(0.0322)\end{array}$ & $\begin{array}{l}4.6663^{* * *} \\
(0.0322)\end{array}$ & $\begin{array}{c}4.6887^{* * * *} \\
(0.0324)\end{array}$ \\
\hline Physical Property Features & $\mathrm{Y}$ & $\mathrm{Y}$ & $\mathrm{Y}$ & $\mathrm{Y}$ \\
\hline District Fixed Effects & $\mathrm{Y}$ & $\mathrm{Y}$ & $\mathrm{Y}$ & $\mathrm{Y}$ \\
\hline Year $\times$ Month Fixed Effects & $\mathrm{Y}$ & $\mathrm{Y}$ & $\mathrm{Y}$ & $\mathrm{Y}$ \\
\hline Observations & 76,465 & 76,465 & 76,465 & 76,465 \\
\hline R-squared & 0.807 & 0.808 & 0.807 & 0.809 \\
\hline
\end{tabular}

Notes: Heteroskedasticity adjusted robust standard errors are reported in parentheses. ${ }^{* * *}$ denotes statistical significance at the $1 \%$ level, respectively.

\section{References}

1. Blakely, E.J.; Snyder, M.G. Fortress America: Gated Communities in the United States; Brookings Institution: Washington, DC, USA, 1999.

2. Grant, J.; Mittelsteadt, L. Types of Gated Communities. Environ. Plan. B Plan. Des. 2004, 31, 913-930. [CrossRef]

3. Le Goix, R.; Webster, C.J. Gated Communities: Gated Communities. Geogr. Compass 2008, 2, 1189-1214. [CrossRef]

4. Plaut, P.O. The Characteristics and Tradeoffs of Households Choosing to Live in Gated Communities. Environ. Plan. B Plan. Des. 2011, 38, 757-775. [CrossRef]

5. Webster, C. Gated Cities of Tomorrow. Town Plan. Rev. 2001, 72, 149-170. Available online: https://www.jstor.org/stable/401124 45 (accessed on 20 June 2021). [CrossRef]

6. Atkinson, R.; Flint, J. Fortress UK? Gated Communities, the Spatial Revolt of the Elites and Time-Space Trajectories of Segregation. Hous. Stud. 2004, 19, 875-892. [CrossRef]

7. Borsdorf, A.; Hidalgo, R. New Dimensions of Social Exclusion in Latin America: From Gated Communities to Gated Cities, the Case of Santiago de Chile. Land Use Policy 2008, 25, 153-160. [CrossRef]

8. Liu, C. Institutional Logics of Ungating Communities in China. Habitat Int. 2019, 94, 102065. [CrossRef]

9. Douglass, M.; Wissink, B.; van Kempen, R. Enclave Urbanism in China: Consequences and Interpretations. Urban Geogr. 2012, 33, 167-182. [CrossRef]

10. He, S. Evolving Enclave Urbanism in China and Its Socio-Spatial Implications: The Case of Guangzhou. Soc. Cult. Geogr. 2013, 14, 243-275. [CrossRef]

11. Huang, Y. Collectivism, Political Control, and Gating in Chinese Cities. Urban Geogr. 2006, 27, 507-525. [CrossRef]

12. Miao, P. Deserted Streets in a Jammed Town: The Gated Community in Chinese Cities and Its Solution. J. Urban Des. 2003, 8 , 45-66. [CrossRef] 
13. Hook, D.; Vrdoljak, M. Gated Communities, Heterotopia and a "Rights" of Privilege: A 'heterotopology' of the South African Security-Park. Geoforum 2002, 33, 195-219. [CrossRef]

14. Breitung, W. Enclave Urbanism in China: Attitudes towards Gated Communities in Guangzhou. Urban Geogr. 2012, 33, 278-294. [CrossRef]

15. Li, S.-M.; Zhu, Y.; Li, L. Neighborhood Type, Gatedness, and Residential Experiences in Chinese Cities: A Study of Guangzhou. Urban Geogr. 2012, 33, 237-255. [CrossRef]

16. Low, S. Behind the Gates: Life, Security, and the Pursuit of Happiness in Fortress America; Routledge: London, UK, 2004.

17. Sun, G.; Webster, C. The Security Grills on Apartments in Gated Communities: Trading-off 3D and 2D Landscapes of Fear in China. Cities 2019, 90, 113-121. [CrossRef]

18. Yip, N.M. Walled without Gates: Gated Communities in Shanghai. Urban Geogr. 2012, 33, 221-236. [CrossRef]

19. Chen, Z. Beijing Strengthens Community Prevention, Control as COVID-19 Cases Reappear. Xinhua Net, 9 September 2020. Available online: http://www.xinhuanet.com/english/2020-06/15/c_139141246_2.htm (accessed on 20 June 2021).

20. Zhou, H. Beijing Shows How Coronavirus' Impact on the Economy Can be Contained. South China Morning Post, 1 July 2020. Available online: https:/ /www.scmp.com/comment/opinion/article/3091029/beijing-shows-how-coronavirus-impacteconomy-can-be-contained (accessed on 20 June 2021).

21. Hong, Y.; Li, Y. Housing Prices and Investor Sentiment Dynamics: Evidence from China Using a Wavelet Approach. Fin. Res. Lett. 2020, 35, 101300. [CrossRef]

22. Wang, Z.; Hui, E.C.-M. Fundamentals and Market Sentiment in Housing Market. Hous. Theory Soc. 2017, 34, 57-78. [CrossRef]

23. Acuto, M.; Larcom, S.; Keil, R.; Ghojeh, M.; Lindsay, T.; Camponeschi, C.; Parnell, S. Seeing COVID-19 through an Urban Lens. Nat. Sustain. 2020, 3, 977-978. [CrossRef]

24. De Groot, J.; Lemanski, C. COVID-19 Responses: Infrastructure Inequality and Privileged Capacity to Transform Everyday Life in South Africa. Environ. Urban. 2021, 33, 255-272. [CrossRef]

25. Hamidi, S.; Sabouri, S.; Ewing, R. Does Density Aggravate the COVID-19 Pandemic?: Early Findings and Lessons for Planners. J. Am. Plan. Assoc. 2020, 86, 495-509. [CrossRef]

26. Wu, F. Rediscovering the 'Gate' under Market Transition: From Work-Unit Compounds to Commodity Housing Enclaves. Hous. Stud. 2005, 20, 235-254. [CrossRef]

27. Wu, F. Gated and Packaged Suburbia: Packaging and Branding Chinese Suburban Residential Development. Cities 2010, 27, 385-396. [CrossRef]

28. Coy, M.; Pöhler, M. Gated Communities in Latin American Megacities: Case Studies in Brazil and Argentina. Environ. Plan. B Plan. Des. 2002, 29, 355-370. [CrossRef]

29. Jürgens, U.; Gnad, M. Gated Communities in South Africa-Experiences from Johannesburg. Environ. Plan. B Plan. Des. 2002, 29, 337-353. [CrossRef]

30. Morange, M.; Folio, F.; Peyroux, E.; Vivet, J. The Spread of a Transnational Model: 'Gated Communities' in Three Southern African Cities (Cape Town, Maputo and Windhoek): 'Gated Communities' in Cape Town, Maputo and Windhoek. Int. J. Urban Reg. Res. 2012, 36, 890-914. [CrossRef]

31. Pow, C.-P.; Kong, L. Marketing the Chinese Dream Home: Gated Communities and Representations of the Good Life in (Post-)Socialist Shanghai. Urban Geogr. 2007, 28, 129-159. [CrossRef]

32. Wu, F.; Webber, K. The Rise of "Foreign Gated Communities" in Beijing: Between Economic Globalization and Local Institutions. Cities 2004, 21, 203-213. [CrossRef]

33. He, S. Homeowner Associations and Neighborhood Governance in Guangzhou, China. Eurasian Geogr. Econ. 2015, 56, 260-284. [CrossRef]

34. Lu, T.; Zhang, F.; Wu, F. The Variegated Role of the State in Different Gated Neighbourhoods in China. Urban Stud. 2020, 57, 1642-1659. [CrossRef]

35. Cai, R.; He, S. Governing Homeowner Associations in China's Gated Communities: The Extension of State Infrastructural Power and Its Uneven Reach. Urban Geogr. 2021, 1-23. [CrossRef]

36. LaCour-Little, M.; Malpezzi, S. Gated Communities and Property Values. Working Paper. 2001. Available online: http: //waterfrontlakeway.com/DNA/wp-content/uploads/2013/12/Gated-communities.pdf (accessed on 20 June 2021).

37. Bible, D.S.; Hsieh, C. Gated communities and residential property values. Apprais. J. 2001, 140-146.

38. Pompe, J. The Effect of a Gated Community on Property and Beach Amenity Valuation. Land Econ. 2008, 84, 423-433. [CrossRef]

39. Soyeh, K.W.; Asabere, P.K.; Owusu-Ansah, A. Price and Rental Differentials in Gated versus Non-Gated Communities: The Case of Accra, Ghana. Hous. Stud. 2020, 1-18. [CrossRef]

40. McDonell, S. Coronavirus: Fear of Second Wave in Beijing after Market Outbreak. BBC, 13 June 2020. Available online: https:/ / www.bbc.com/news/world-asia-china-53034924 (accessed on 20 June 2021).

41. Mozur, P.; Zhong, R.; Krolik, A. In Coronavirus Fight, China Gives Citizens a Color Code, with Red Flags. The New York Times, 2 March 2020. Available online: https:/ /www.nytimes.com/2020/03/01/business/china-coronavirus-surveillance.html (accessed on 20 June 2021).

42. Luo, Q. Epidemic Controls are Difficult in Super Large Housing Estates. Beijing Daily, 9 September 2020. Available online: http:/ /bjrb.bjd.com.cn/html/2020-03/06/content_12449937.htm (accessed on 20 June 2021). 
43. Deutskens, E.; de Ruyter, K.; Wetzels, M.; Oosterveld, P. Response Rate and Response Quality of Internet-Based Surveys: An Experimental Study. Mark. Lett. 2004, 15, 21-36. [CrossRef]

44. Guo, J.; Qu, X. Spatial Interactive Effects on Housing Prices in Shanghai and Beijing. Reg. Sci. Urban Econ. 2019, 76, 147-160. [CrossRef]

45. Huang, B.; Zhou, Y.; Li, Z.; Song, Y.; Cai, J.; Tu, W. Evaluating and Characterizing Urban Vibrancy Using Spatial Big Data: Shanghai as a Case Study. Environ. Plan. B Urban Anal. City Sci. 2020, 47, 1543-1559. [CrossRef]

46. Sun, G.; Webster, C.; Chiaradia, A. Ungating the City: A Permeability Perspective. Urban Stud. 2018, 55, 2586-2602. [CrossRef]

47. Mittal, J.; Byahut, S. Scenic Landscapes, Visual Accessibility and Premium Values in a Single Family Housing Market: A Spatial Hedonic Approach. Environ. Plan. B Urban Anal. City Sci. 2019, 46, 66-83. [CrossRef] 